\title{
Электрохимический синтез и сорбционные характеристики полимеров с молекулярными отпечатками кленбутерола и рактопамина
}

\author{
(C) 2020 Ермолаева Т.Н., Фарафонова О.В., Носикова Е.В. \\ ФГБОУ ВО «Липецฺкий государственный технический университет», Липеик
}

Поступила в редакцию 24.02.2020 г.

DOI: $10.17308 /$ sorpchrom.2020.20/2776

Исследованы условия электрохимического синтеза на поверхности электрода сенсора высокоаффинного тонкопленочного покрытия на основе полимера с молекулярными отпечатками кленбутерола и рактопамина методом циклической вольтамперометрии с линейной разверткой потенциала в интервале -0.2-0.8 В, Электрохимический синтез ПМО проводили в трехэлектродной ячейке: в качестве рабочего электрода использовали пьезокварцевый резонатор АТ-среза, вспомогательного электрода пластины из нержавеющей стали, электрода сравнения - хлоридсеребряный электрод. Описаны условия получения пленок ПМО на основе метиленового синего или пиррола, сополимера пиррола и анилина, а также пиррола и разрыхляющих реагентов - гидрохинона, пирокатехина, резорцина. Для оценки качества электросинтезированного покрытия контролировали топографию поверхности (метод атомной силовой микроскопии); изменение массы пленки ПМО в процессе ее формирования, а также после удаления и повторного встраивания молекул темплата (метод пьезокварцевого микровзвешивания). Установлено, что формирование устойчивых полимерных пленок на основе полипиррола или полипиррола с гидрохиноном происходит в течение одного цикла полимеризации, полипиррола и анилина двух циклов, а метиленового синего - 60 циклов полимеризации. Показано, что при получении пленок ПМО кленбутерола и рактопамина на основе пиррола и гидрохинона или метиленового синего происходит образование структур, с высокой концентрацией устойчивых молекулярных отпечатков.

Аналитический сигнал сенсора регистрировали относительно сенсора с неимпринтированным полимером (НИП) для исключения вклада в сигнал неспецифических взаимодействий на поверхности сенсора. Сенсоры на основе электросинтезированных слоев ПМО протестированы при анализе модельных растворов кленбутерола и образцов мяса. Градуировочные графики линейны в диапазоне 7.5-30 мкг $/ \mathrm{cm}^{3}$ (для сенсоров на основе полипиррола и гидрохинона) и 11.3-60.0 мкг $/ \mathrm{cm}^{3}$ (для сенсоров на базе метиленового синего), предел обнаружения кленбутерола равен (мкг/см³) 5.6 и 0.46 соответственно.

Ключевые слова: полимеры с молекулярными отпечатками, электрополимеризация, кленбутерол, рактопамин.

\section{Введение}

В качестве распознающих элементов химических сенсоров перспективно применение полимеров с молекулярными отпечатками (ПМО), полученных методами электрополимеризации, обеспечивающих воспроизводимое получение ультратонких пленок непосредственно на поверхности электрода [1-4]. Такие пленки характеризуются высокой химической стабильностью и адгезией к металлическому электроду. Применение метода электрополимеризации позволяет сократить продолжительность получения покрытия и упростить процедуру анализа. 
Сорбционные покрытия на основе ПМО, положительно зарекомендовали себя при применении в пьезоэлектрических сенсорах для чувствительного и селективного определения различных соединений [5].

Электросинтез ПМО, как правило, осуществляется методом циклической вольтамперометрии (BА) с линейной разверткой потенциала. Свойства пленок ПМО существенно зависят от природы функционального мономера и его концентраций в реакционной смеси, дизайна молекулы темплата. Важную роль играет природа и концентрация фонового электролита, влияющего на морфологию поверхности полимерного слоя и скорость пленкообразования. Исследования показали, что при тщательно выбранных условиях (например, при достаточно низкой концентрации мономера и медленной скорости полимеризации) осаждение в ходе процедуры электросинтеза происходит стабилизированном образом, то есть масса и толщина пленки увеличивается пропорционально количеству ВА циклов. Такие полимерные пленки стабильны в водных и органических растворителях и позволяют осуществлять молекулярное распознавание целевых аналитов в различных средах $[6,7]$.

Цель данной работы - создание высокоаффинного тонкопленочного рецепторного покрытия на основе полимера с молекулярными отпечатками кленбутерола и рактопамина на поверхности золотого электрода пьезоэлектрического сенсора электрохимическим способом.

\section{Эксперимент}

Электрохимический синтез ПМО осуществлялся в трехэлектродной ячейке в потенциодинамическом режиме с циклической разверткой потенциала (электрохимическая рабочая станция «Zive SP2», Южная Корея). В качестве рабочего электрода использован пьезокварцевый резонатор АТ-среза с собственной частотой колебаний 10 МГц, 8 мм в диаметре с золотыми электродами диаметром 5 мм на двух сторонах (ЭТНА, Россия), помещенный в специальную ячейку, позволяющую формировать полимерный слой только на одной стороне резонатора, вспомогательного электрода пластины из нержавеющей стали, хлоридсеребряного электрода, выполняющего роль электрода сравнения. Аналитический сигнал измеряли при комнатной температуре $\left(25 \pm 5^{\circ} \mathrm{C}\right)$ на воздухе после высушивания сенсора до постоянной массы на установке на основе генератора колебаний Б5-30 и цифрового модуля Discope (Бафика, Россия), а также персонального компьютера $[8,9]$.

В работе в качестве мономеров применяли пиррол (Ру) («AcrosOrganics», США), анилин (An) («Вектон», Россия) или метиленовый синий («Реахим», Россия), а в качестве сополимеров, облегчающих включение молекул кленбутерола (Klb) или рактопамина (Rac) («Abcam», Великобритания) в структуру полимера, гидрохинон, пирокатехин, резорцин («Реахим», Россия).

В качестве фоновых электролитов применяли фосфатный (100 мM $\mathrm{K}_{2} \mathrm{HPO}_{4}+\mathrm{HCl} \quad(\mathrm{pH}=9.3), \quad 0.00025$ моль/дм $\left.{ }^{3}\right)$, боратный $\left(100 \mathrm{mM} \mathrm{NaB}_{4} \mathrm{O}_{7}+\mathrm{HCl}\right.$ $(\mathrm{pH}=9.0)+100$ мМ $\mathrm{NaNO}_{3}, 0.00025$ моль/дм $\left.{ }^{3}\right)$, фосфатно-боратный $\left(0.1 \mathrm{M} \mathrm{K}_{2} \mathrm{HPO}_{4}\right.$ $+0.05 \mathrm{M} \mathrm{NaB}_{4} \mathrm{O}_{7},(\mathrm{pH}=9.0), 0.00025$ моль/дм $\left.{ }^{3}\right)$ буферные растворы.

Равномерность распределения электрогенерированного слоя ПМО на поверхности золотого электрода контролировали методом оптической микроскопии (микроскоп МИМ-8, Россия); топографию поверхности полимерной пленки - методом атомной силовой микроскопии ACM (сканирующий зондовый микроскоп «Solver P47PRO», Россия); изменение массы пленки ПМО в процессе ее формирования, а также при удалении или повторном встраивании молекул темплата - методом пьезокварцевого микровзвешивания.

$\boldsymbol{E}$ рмолаева и др. / Сорбционные и хроматографические процессы. 2020. Т. 20. № 2. С. 223-230 
Массу покрытия сенсора $\Delta \mathrm{m}$ рассчитывалась по уравнению Зауэрбрея: $\Delta \mathrm{F}=2.3 \cdot 10^{6} \cdot \mathrm{F}_{0}^{2} \cdot \Delta \mathrm{m} / \mathrm{S}$, где $\mathrm{S}$ - площадь электрода пьезокварцевого сенсора, $\mathrm{cm}^{2}$ (0.10066), $\mathrm{F}_{0}$ - базовая частота резонатора, Гц; $\Delta \mathrm{F}=\mathrm{F}_{1}-\mathrm{F}_{2}$, где $\mathrm{F}_{1}$ и $\mathrm{F}_{2}$ - частота колебаний сенсора до и после полимеризации, Гц; толщину электрополимеризованной пленки по уравнению $\mathrm{h}=0.043 \cdot \Delta \mathrm{f}$, (мкм). Аналитический сигнал сенсора регистрировали относительно сенсора с неимпринтированным полимером (НИП) для исключения вклада в сигнал неспецифических взаимодействий на поверхности сенсора. Массу удаленного с поверхности ПМО и повторно встроенного кленбутерола или рактопамина рассчитывали по разности между массой пленки полимера до и после экстракции темплата. Концентрацию поверхностных отпечатков темплата на поверхности ПМО $\left(\mathrm{R}_{\max }\right)$ и отпечатков после регенерации поверхности $\left(\mathrm{R}^{\prime}\right)$ рассчитывали $[8,10]$, как: $\mathrm{R}=\mathrm{m}_{\mathrm{BC}} /\left(\mathrm{S} \cdot \mathrm{M}_{\mathrm{tem})}\right.$, мкмоль $/ \mathrm{cm}^{2}$, где $\mathrm{m}_{\mathrm{BC}}-$ масса удаленных молекул темплата, мкг; $\mathrm{M}_{\mathrm{tem}}$ - молекулярная масса кленбутерола или рактопамина.

\section{Обсуждение результатов}

К полимерному покрытию пьезоэлектрического сенсора на основе ПМО предъявляются следующие требования:

- оно должно полностью покрывать всю поверхность электрода равномерным слоем, характеризоваться высокой адгезией к золотому электроду, что делает возможным его многократное применение;

- иметь пространственную структуру, облегчающую встраивание молекул темплата и извлечение его при регенерации поверхности, невысокую массу и толщину, обеспечивать воспроизводимость аналитического сигнала при многократных измерениях.

Изучены условия получения пленок ПМО на основе индивидуального мономера - метиленового синего и пиррола, а также сополимера пиррола и анилина, сополимера пиррола с кросс-реагентами - гидрохинон, пирокатехин и резорцин. При выборе условий электрополимеризации пиррола руководствовались исследованиями, выполненными ранее [11-13]. Предполимеризационная смесь имела следующий состав: $0.2 \mathrm{M}$ пиррола, $0.1 \mathrm{M}$ хлорида натрия, $0.03 \mathrm{Mг} / \mathrm{cm}^{3} \mathrm{Klb}$ или Rac. Полимеризация проводилась в потенциодинамическом режиме с циклической разверткой потенциала в интервале -0.2-0.8 В, со скоростью $10 \mathrm{mB} / \mathrm{c}$ в течение одного цикла. Отмечено увеличение анодного пика на вольтамперограмме при электросинтезе пленок ПМО по сравнению с неимпринтированными пленками пиррола, что указывает на усиление связывания молекул мономера в присутствие кленбутерола и рактопамина. Однако, воспроизводимых по массе покрытий (тпмо) с фиксированной концентрацией поверхностных молекулярных отпечатков получить не удается (табл. 1). Сравнительный анализ данных, полученных методом пьезокварцевого микровзвешивания и АСМ, свидетельствует о снижении массы встраиваемого темплата и поверхностной концентрации молекулярных отпечатков при повторном встраивании темплата (R, ммоль/см $\left.{ }^{2}>\mathrm{R}^{\prime}\right)$.

Таблица 1. Характеристика электрополимеризованных слоев ПМО Klb и Rac

\begin{tabular}{|c|c|c|c|c|}
\hline $\mathrm{m}_{\Pi м \mathrm{O}}$, МКг & $\Delta \mathrm{m}_{\mathrm{BC}}$, МкГ & $\mathrm{R}$, ммоль $/ \mathrm{cm}^{2}$ & $\Delta \mathrm{m}_{\text {ПвС }}$, мкг & $\mathrm{R}^{\prime}$, ммоль/см ${ }^{2}$ \\
\hline 1 & 2 & 3 & 4 & 5 \\
\hline \multicolumn{5}{|c|}{ Пленки ПМО Klb на основе пиррола } \\
\hline 7.6 & $1.9 \pm 0.5$ & 0.70 & $0.1 \pm 0.06$ & 0.04 \\
\hline \multicolumn{5}{|c|}{ Пленки ПМО Klb на основе пиррола и гидрохинона } \\
\hline 6.7 & $1.8 \pm 0.1$ & 0.60 & $1.3 \pm 0.2$ & 0.50 \\
\hline
\end{tabular}

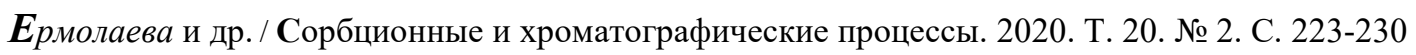




\begin{tabular}{|c|c|c|c|c|}
\hline 1 & 2 & 3 & 4 & 5 \\
\hline \multicolumn{5}{|c|}{ Пленки ПМО Rac на основе пиролла и гидрохинона } \\
\hline 24.6 & $8.4 \pm 0.9$ & 2.13 & $6.5 \pm 0.8$ & 1.80 \\
\hline \multicolumn{5}{|c|}{ Пленки ПМО Klb на основе сополимера пиррола и анилина } \\
\hline 5.3 & $1.1 \pm 0.3$ & 0.42 & $1.8 \pm 0.2$ & 0.25 \\
\hline \multicolumn{5}{|c|}{ Пленки ПМО Klb на основе метиленового синего (боратный буферный раствор) } \\
\hline 2.6 & $1.7 \pm 0.2$ & 0.62 & $1.0 \pm 0.1$ & 0.40 \\
\hline \multicolumn{5}{|c|}{ Пленки ПМО Klb на основе метиленового синего (фосфатный буферный раствор) } \\
\hline 2.4 & $2.0 \pm 0.4$ & 0.8 & $0.3 \pm 0.1$ & 0.11 \\
\hline
\end{tabular}

Для повышения сорбционной активности предложено вводить в состав предполимеризационной смеси разрыхляющие агенты (кросс-мономеры), обеспечивающие поперечную сшивку слоев полимера, снижение плотности плёнки за счет формирования трёхмерной структуры сайтов молекулярного распознавания. Применение пирокатехина или резорцина (0.001-0.01 M) не обеспечивало стабильных и воспроизводимых результатов. Равномерное, плотное и однородное покрытие имело высокую массу, что приводило к перегрузке резонатора и срыву частотных колебаний сенсора. Устойчивые пленки ПМО были получены лишь при использовании в качестве кроссмономера гидрохинона (табл. 2) в концентрации 0.005 М. Увеличение концентрации гидрохинона до $0.01 \mathrm{M} \mathrm{приводит} \mathrm{к} \mathrm{получению} \mathrm{тяжелого} \mathrm{неоднородного} \mathrm{полимерного}$ слоя и затрудняет образование устойчивых отпечатков молекул темплата, а уменьшение до $0.001 \mathrm{M} \mathrm{способствует} \mathrm{образованию} \mathrm{рыхлой} \mathrm{структуры,} \mathrm{неоднородно} \mathrm{распреде-}$ ленной на поверхности электрода. Формирование однородного полимерного слоя полипиррол - гидрохинон в среде $0.1 \mathrm{NaCl}, 0.2 \mathrm{M}$ Ру и $0.005 \mathrm{M} \mathrm{C}_{6} \mathrm{H}_{6} \mathrm{O}_{2}$; концентрация $\mathrm{Klb}-30$ мкг $/ \mathrm{cm}^{3}$ методом циклической вольтамперометрии происходит уже на первом цикле развертки потенциала в потенциодинамическом режиме со скоростью $10 \mathrm{mB} / \mathrm{c}$ в диапазоне $-0.2 \div 0.8$ В. При увеличении числа циклов полимеризации встраивание темплата происходит не только в поверхностном слое, но и в объеме полимера, что приводит к образованию пленок с большой массой и толщиной с недоступными для молекул темплата отпечатками.

Таблица 2. Влияние концентрации гидрохинона на свойства ПМО кленбутерола

\begin{tabular}{|c|c|c|c|c|c|c|}
\hline $\mathrm{C}, \mathrm{M}$ & $\mathrm{m}_{\text {пмо, мкг }}$ & $\mathrm{h}$, мкм & $\Delta \mathrm{m}_{\text {ВС, мкг }}$ & $\begin{array}{c}\mathrm{R}, \\
\text { ммоль } / \mathrm{cm}^{2}\end{array}$ & $\Delta \mathrm{m}_{\text {пвС, мкг }}$ & $\begin{array}{c}\mathrm{R}, \\
\text { ммоль } / \mathrm{cm}^{2}\end{array}$ \\
\hline 0.001 & 9.3 & 0.76 & $2.2 \pm 0.7$ & 0.7 & $0.2 \pm 0.06$ & 0.06 \\
\hline 0.005 & 6.7 & 0.55 & $1.8 \pm 0.3$ & 0.6 & $1.3 \pm 0.2$ & 0.5 \\
\hline 0.01 & 12.6 & 1.01 & $5.9 \pm 0.8$ & 2.1 & - & - \\
\hline
\end{tabular}

Методом АСМ установлено увеличение средней шероховатости электросинтезированных пленок на основе полипиррола и гидрохинона в ряду: НИП, ПМО кленбутерола, ПМО кленбутерола после экстракции молекул темплата (рис. 1), а методом пьезокварцевого микровзвешивания показано, что на поверхности такой пленки концентрация поверхностных отпечатков после регенерации сохраняется практически постоянной (табл. 1).

Свойства электросинтезированных пленок ПМО на основе сополимера пиррола и анилина существенно зависят от состава предполимеризационной смеси (табл.3). Сопоставление значений $\Delta \mathrm{m}_{\mathrm{BC}}$ и $\Delta \mathrm{m}_{\Pi B C}, \mathrm{R}$ и $\mathrm{R}$ ' показало, что только при использовании $0.2 \mathrm{M}$ анилина и двух циклов полимеризации приводит к образованию устойчивых покрытий, обеспечивающих максимальное повторное встраивание молекул темплата, увеличение концентрации анилина до $0.4 \mathrm{M}$ не обеспечивает получение

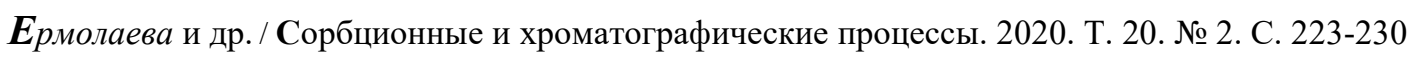


однородного полимерного слоя, а уменьшение до $0.005 \mathrm{M}$ - исключает его образование.
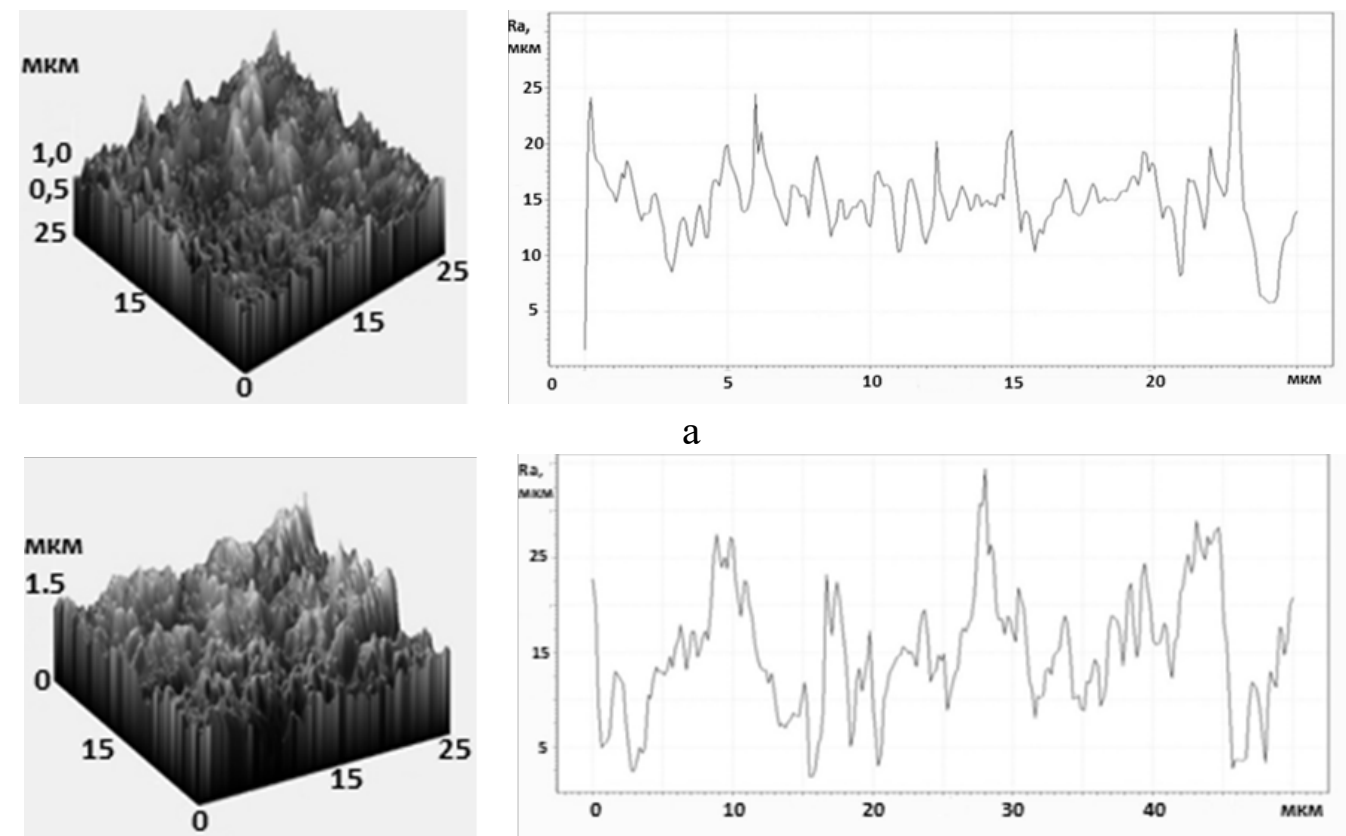

6
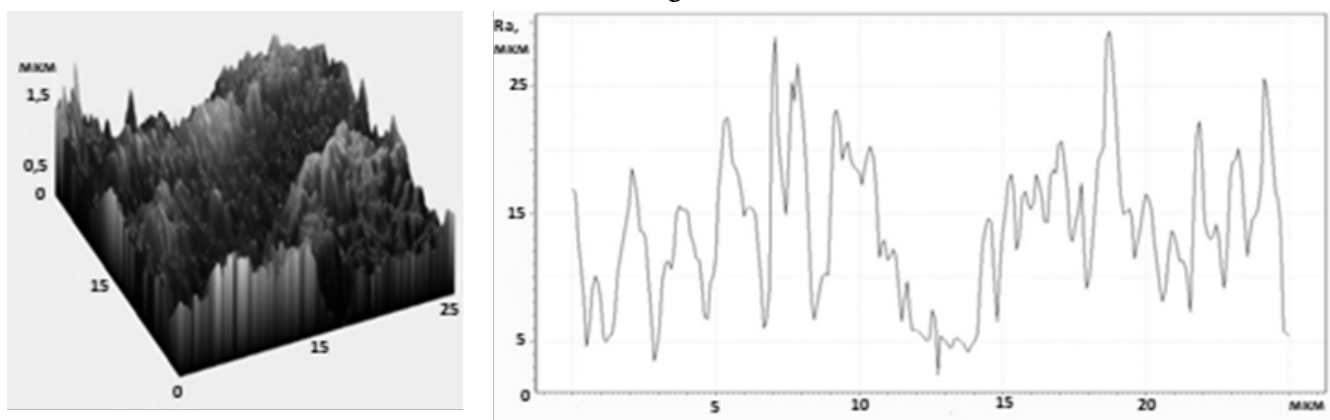

Рис. 1. ACM-3D изображения и профиль $(25 \times 25$ мкм $)$ поверхности полипиррольной пленки с гидрохиноном НИП, $\mathrm{Ra}=134 \pm 8$ нм (a); слоя ПМО кленбутерола, $\mathrm{Ra}=237 \pm 18$ нм (б); слоя ПМО кленбутерола после удаления темплата, $\mathrm{Ra}=295 \pm 11$ нм (в)

Таблица 3. Влияние концентрации анилина на характеристики пленок ПМО

\begin{tabular}{|c|c|c|c|c|c|c|c|}
\hline $\begin{array}{c}\text { С (An), } \\
\text { M }\end{array}$ & $\mathrm{N}$ & Мпмо, мкг & $\mathrm{h}$, мкм & $\Delta \mathrm{m}_{\text {ВС, мкг }}$ & $\begin{array}{c}\mathrm{R}, \\
\text { ммоль } / \mathrm{cm}^{2}\end{array}$ & $\Delta \mathrm{m}_{\text {ПвС, мкг }}$ & $\begin{array}{c}\mathrm{R} \\
\text { ммоль }\end{array} \mathrm{cm}^{2}$ \\
\hline 1 & 2 & 3 & 4 & 5 & 6 & 7 & 8 \\
\hline \multirow{2}{*}{0.1} & 1 & 0.6 & 0.06 & $0.4 \pm 0.2$ & 0.15 & $0.05 \pm 0.02$ & 0.02 \\
\cline { 2 - 8 } & 2 & 1.1 & 0.11 & $0.6 \pm 0.3$ & 0.23 & $0.05 \pm 0.03$ & 0.02 \\
\hline \multirow{2}{*}{0.2} & 1 & 2.4 & 0.23 & $0.8 \pm 0.3$ & 0.30 & $0.10 \pm 0.03$ & 0.04 \\
\cline { 2 - 8 } & $\mathbf{2}$ & $\mathbf{5 . 3}$ & $\mathbf{0 . 4 0}$ & $\mathbf{1 . 1} \pm \mathbf{0 . 2}$ & $\mathbf{0 . 4 2}$ & $\mathbf{1 . 7 9} \pm \mathbf{0 . 0 4}$ & $\mathbf{0 . 2 5}$ \\
\hline \multirow{2}{*}{0.4} & 1 & 3.7 & 0.35 & $0.8 \pm 0.4$ & 0.27 & $0.04 \pm 0.02$ & 0.01 \\
\cline { 2 - 8 } & 2 & 8.0 & 0.59 & $0.6 \pm 0.3$ & 0.21 & - & - \\
\hline
\end{tabular}

Известно, что при электрополимеризации метиленового синего (MB) на поверхности золотого электрода формируется равномерный тонкий слой в щелочной среде в течение 25-100 циклов полимеризации $[14,15]$. Формирование слоя ПМО на основе MB осуществляли из раствора, содержащего 0.76 ммоль МВ и 30 мкг $/ \mathrm{cm}^{3} \mathrm{Klb}$ 
в присутствии фосфатного, боратного или фосфатно-боратного буферного раствора мономера, при скорости сканирования $100 \mathrm{mB} / \mathrm{c}$ в интервале $-0.2 \div 0.8$ В в течение 60 циклов. На циклической вольтамперограмме, как и при синтезе пленок на основе МВ в отсутствие $\mathrm{Klb}$, присутствуют два пика, соответствующие передаче двух электронов в результате окислительно-восстановительной реакции, и третий пик, отвечающий только процессу окисления МВ $[14,15]$. В процессе формированию полимерной пленки практически все пики смещаются в сторону положительных потенциалов и значения тока смещенных пиков возрастают с увеличением числа потенциальных циклов. Это указывает на формирование полимерной пленки на золотом электроде сенсора и повышение ее толщины с возрастанием числа циклов полимеризации.

Сопоставление значений $\Delta \mathrm{m}_{\mathrm{BC}}$, и $\Delta \mathrm{m}_{\Pi \mathrm{BC}}, \mathrm{R}$, ммоль/см${ }^{2}$ и $\mathrm{R}$, ммоль/см ${ }^{2}$ образовавшегося рецепторного слоя полиметиленового синего показало (табл. 1), что только при использовании боратного буфера происходит максимальное повторное встраивание молекул темплата.

$\mathrm{C}$ помощью аналитического сигнала сенсора $\Delta \mathrm{F}$, измеренного после электросинтеза ПМО слоя, удаления молекул темплата и его повторного встраивания, были рассчитаны аналитические характеристики сенсоров на основе ПМО (табл. 4). Как видно из приведенных данных, максимальная концентрационная чувствительность сенсора и более низкое значение предела обнаружения наблюдаются для ПМО слоя на основе МВ.

Таблица 4. Характеристика распознающего слоя пьезоэлектрического сенсора на основе сополимера Ру гидрохинона (1) и МВ (2)

\begin{tabular}{|c|c|c|}
\hline \multirow{2}{*}{ Параметр } & \multicolumn{2}{|c|}{ Величина } \\
\cline { 2 - 3 } & 1 & 2 \\
\hline Уравнение градуировочной функции & $\Delta \mathrm{F}=7.4 \mathrm{C}+21$ & $\Delta \mathrm{F}=68.6 \mathrm{C}$ \\
\hline Коэффициент корреляции & 0.94 & 0.97 \\
\hline Линейный диапазон функции, мкг $/ \mathrm{cm}^{3}$ & $7.5-30$ & $11.3-60.0$ \\
\hline Предел обнаружения, мкг $/ \mathrm{cm}^{3}$ & 5.6 & 0.46 \\
\hline
\end{tabular}

Сенсоры на основе ПМО протестированы при определении кленбутерола в мясе (табл. 5).

Таблица 5. Определение кленбутерола в говядине $(\mathrm{P}=0.95 ; \mathrm{n}=3)$.

\begin{tabular}{|c|c|c|c|c|}
\hline Образец & Введено, мкг $/ \mathrm{cm}^{3}$ & Найдено, мкг $/ \mathrm{cm}^{3}$ & Процент открытия, $\%$ & $\mathrm{~S}_{\mathrm{r}}$ \\
\hline 1 & 10.0 & $9.8 \pm 0.3$ & 98.0 & 0.01 \\
\hline 2 & 20.0 & $19.9 \pm 0.2$ & 98.5 & 0.01 \\
\hline
\end{tabular}

\section{Заключение}

Результаты проведенных исследований наглядно демонстрируют преимущество формирования распознающего слоя на основе ПМО методом электрополимеризации. Сенсоры с электросинтезированными распознающими слоями ПМО кленбутерола или рактопамина могут быть использованы для аналитического контроля аналитов в водных средах и мясе.

Исследования выполнены при финансовой поддержке РФФИ

(грант 13-03-97505-р_иентр_а) «Селективность и эффективность молекулярного распознавания и определения гормонов и бэта-агонистов с помощьью пьезоквариевого иммуно- и биомиметического сенсора». 


\title{
Список литературы
}

1. Crapnell R.D., Hudson A., Foster C.W., Eersels, K.et al. // Sensors. 2019. Vol. 19. pp. 1204-1232.

2. Cosnier S. // Electroanalysis. 2005. Vol. 17. No 19. pp. 1701-1712.

3. Li G., Wang Y., Xu H. // Sensors. 2007. Vol. 7, pp. 239-250.

4. Feng L., Liu Y., Tan Y., Hu J. // Biosens. Bioelectron. 2004. Vol. 19. No 11. pp. 1513-1519.

5. Avila M., Zougagh A., Escarpa A. // Trends in Anal. Chem. 2008. Vol. 27. No 1/ pp. 54-65.

6. Карасева НА., Соболева И.Г., Ермолаева Т.Н. // Сорбиионные и хроматографические прочессы. 2013. Т.13. № 1. С. 5-9.

7. Ермолаева Т.Н., Чернышова В.Н., Чеснокова Е.В., Бессонов О.И. // Сорбционные и хроматографические прочессы. 2015. Т. 15. № 2. C. 151-167.
8. Ермолаева Т.Н., Фарафонова О. В., Бессонов О.И. // Сорбиионные и хроматографические прочессы. 2019. Т. 19. № 6. С. 682-690.

9. Karaseva N., Ermolaeva T., Mizaikoff B. // Sens. Actuators, B. 2016. Vol. 225. pp. 199-208.

10. Ермолаева Т.Н., Фарафонова О. В., Бессонов О. И. // Журн. анал. химии. 2019. Т. 74. C. $1-8$.

11. Халхали Р.А. // Электрохимия. 2005. Т. 41. № 9. C. 1071-1078.

12. Ebarvia B.S., Cabanilla S., Sevilla F. // Talanta. 2005. Vol. 66. No 1. pp. 145-152.

13. Maouchea N., Guergouri M., Gam-Derouich S., Jouini M. et al. // J. Electroanal. Chem. 2012. Vol. 685. pp. 21-27.

14. Karyakin A.A., Strakhova A.K., Karyakina E.E., Varfolomeyev S.D. et al. // Synthetic Metals. 1993. Vol. 60. pp. 289-291.

15. Liu J., Mu Sh. // Synthetic Metals. 1999. Vol. 107. pp 159-160.

\section{Electrochemical synthesis and sorption characteristics of polymers with molecular imprints of clenbuterol and ractopamine}

\author{
(C) 2020 Ermolaeva T.N., Farafonova O.V., Nosikova E.V. \\ Lipetsk State Technical University, Lipetsk
}

\begin{abstract}
The method of cyclic voltammetry with linear potential sweep within the range of -0.2-0.8 V was used to study the conditions of electrochemical synthesis on the surface of the sensor electrode of a high-affinity thin film coating based on a polymer with molecular imprints of clenbuterol and ractopamine. The electrochemical synthesis of the MIP was carried out in a three-electrode cell: the working electrode was a piezoelectric resonator of AT-cut, the auxiliary electrode were stainless steel plates, and the reference electrode was a silver chloride electrode. We described the conditions for the production of MIP films based on methylene blue or pyrrole, a copolymer of pyrrole and aniline, as well as pyrrole and disintegrating reagents, hydroquinone, pyrocatechol, and resorcinol. To assess the quality of the electro-synthesized coating, surface topography was monitored (atomic force microscopy method), as well as the change in the mass of the MIP film during its formation and after the removal and re-incorporation of template molecules (the method of piezoelectric quartz micro-weighing). It was established that the formation of stable polymer films based on polypyrrole or polypyrrole with hydroquinone occurs within one polymerisation cycle, polypyrrole and aniline occurs within two cycles, and methylene blue occurs within 60 polymerisation cycles. It was shown that the production of clenbuterol and ractopamine MIP films based on pyrrole and hydroquinone or methylene blue results in the formation of structures with a high concentration of stable molecular imprints.

The analytical signal of the sensor was recorded against the sensor with a non-imprinted polymer (NIP) to exclude the contribution of non-specific interactions to the signal on the surface of the sensor. Sensors based on electro-synthesised MIP layers were tested in the analysis of model solutions of clenbuterol and meat samples. Graduation graphs are linear in the range of 7.5-30 $\mu \mathrm{g} / \mathrm{ml}$ (for sensors based on polypyrrole and hydroquinone) and $11.3-60.0 \mu \mathrm{g} / \mathrm{ml}$ (for sensors based on methylene blue), the detection limit of clenbuterol is $(\mu \mathrm{g} / \mathrm{ml}) 5.6$ and 0.46 , respectively.
\end{abstract}

Keywords: polymers with molecular imprints, electropolymerization, clenbuterol, ractopamine. 


\section{References}

1. Crapnell R.D., Hudson A., Foster C.W., Eersels K. et al., Sensors, 2019, Vol. 19, pp. 1204-1232.; doi.org/10.3390/s19051204

2. Cosnier S., Electroanalysis, 2005, Vol. 17, No 19, pp. 1701-712. doi.org/10.1002/elan.200503308

3. Li G., Wang Y., Xu H., Sensors, 2007, Vol. 7, pp. 239-250.

4. Feng L., Liu Y., Tan Y., Hu J., Biosens. Bioelectron., 2004, Vol. 19, No 11, pp. 1513-1519.

5. Avila M., Zougagh A., Escarpa A., Trends in Anal. Chem., 2008, Vol. 27, No 1, pp. 54-65.

6. Karaseva NA., Soboleva I.G., Ermolaeva T.N., Sorbtsionnye $i$ khromatograficheskie protsessy, 2013, Vol. 13, No 1, pp. 5-9.

7. Ermolaeva T.N., Chernyshova V.N., Chesnokova E.V., Bessonov O.I., Sorbtsionnye $i$ khromatograficheskie protscessy, 2015, Vol. 15, No 2, pp. 151-167.

Ермолаева Татьяна Николаевна - профессор кафедры химии, д.Х.н., Липецкий государственный технический университет, Липецк

Фарафонова Ольга Вячеславовна - доцент кафедры химии, к.х.н., Липецкий государственный технический университет, Липецк

Носикова Екатерина Викторовна - студент кафедры химии, Липецкий государственный технический университет, Липецк
8. Ermolaeva T.N., Farafonova O. V., Bessonov O.I., Sorbtsionnye i khromatograficheskie protsessy, 2019, Vol. 19, No 6, pp. 682-690.

9. Karaseva N., Ermolaeva T., Mizaikoff B., Sens. Actuators B, 2016, Vol. 225, pp. 199-208.

10. Ermolayeva T.N., Farafonova O.V., Bessonov O.I., J Anal. Chem., 2019, Vol. 74, No 2, pp. 1-8.

11. Khalkhali R.A., Electrokhimiya, 2005, Vol. 41, No 9, pp. 1071-1078.

12. Ebarvia B.S., Cabanilla S., Sevilla F., Talanta, 2005, Vol. 66, No 1, pp.145-152.

13. Maouchea N., Guergouri M., Gam-Derouich S., Jouini M. et al., J. Electroanal. Chem., 2012, Vol. 685, pp. 21-27.

14. Karyakin A.A., Strakhova A.K., Karyakina E.E., Varfolomeyev S.D. et al., Synthetic Metals., 1993, Vol. 60, pp. 289-291.

15. Liu J., Mu Sh., Synthetic Metals., 1999, Vol. 107, pp 159-160.

Ermolaeva Tatyana N. - prof., grand Ph.D (chemistry), department of chemistry, Lipetsk State Technical University, Lipetsk, e-mail: etn@stu.lipetsk.ru

Farafonova Olga V. - associate prof., Ph.D. (chemistry), department of chemistry, Lipetsk State Technical University, Lipetsk, e-mail: farafonova.ov@mail.ru

Nosikova Catherine V. - student, department of chemistry, Lipetsk State Technical University, Lipetsk 